\title{
Evaluation of Quality Parameters in Raw Meat Used for Processing in the Fast Food Industry
}

\author{
Alexandra TĂBĂRAN ${ }^{1 *}$, Sorin Daniel DAN ${ }^{1}$, Oana REGET ${ }^{1}$, Marian MIHAIU ${ }^{1}$ \\ ${ }^{1}$ Faculty of Veterinary Medicine, University of Agricultural Science and Veterinary Medicine Cluj-Napoca, \\ Manastur Street. 3-5, 400372, Cluj-Napoca, Romania. \\ * corresponding author: lapusan_alexandra@yahoo.com
}

Bulletin UASVM Veterinary Medicine 76(1)/2019

Print ISSN 1843-5270; Electronic ISSN 1843-5378

doi:10.15835/buasvmcn-vm: 2018.0035

\begin{abstract}
The aim was to evaluate the quality aspects of raw meat destined for processing in fast-food units and to compare it with that of meat obtained in the traditional systems. Our study revealed that the water holding capacity (WHC) in poultry meat obtained in the industrial systems and used for processing in fast-foods is very variable and also very high compared to the one obtained in the traditional systems. When examining sensorially the quality aspects we found that the colour of the poultry meat (legs) is whiter, paler and in the breast areas we noticed a pathology known the "wooden breast". In the case of pork meat, we obtained similar results, the industrially obtained meat showing a lighter colour and lower consistency. The protein percentage was correlated with the low quality of the meat obtained in the industrial system. Raw meat destined for processing in the fastfood units should be improved given the lower quality revealed. Measures should be taken also in the production units so as to prevent the pathological lesions found, such as "wooden breast" in poultry meat which we found to be very often observed.
\end{abstract}

Keywords: colour, wooden breast, protein, pork

\section{Introduction}

Providing a high quality standard for meat products is a general issue adressed by all producers, retailers and processors within this industry. Many factors contribute to the quality of the raw meat and studies concerning possible means to improve it have already been published (Petracci et al., 2001; Fletcher, 2002; Brewer et al., 2004). Until know it is generally agreed that meat should first of all gurantee consumer's safety and proper technolgical characteristics and finally to ensure its authenticity (Monin, 1998). There is no standard definition regarding the term quality of meat which can enhance all the quality aspects important during the production stages. Health and ethical aspects can also be as important for some in the same way as the technolopgical and sensorial ones (Abdullah et al., 2010; Edwards et al., 2003). The factors which influence meat quality are varied. It is essential to take into account the aspects related to animal feeding systems and breeding conditions. There are a number of studies related to compositional variation according to the breeding system and the beneficial aspects of traditional breeding (Brewer et al., 2004; Tomovic et al., 2014a). Unfortunetly in the fast food industry the meat is provided by large scale units and normally the quality aspects are not the same. In the industrial and intensive breeding systems, animals do not have the same space or feeding regime so the carcasses show more fat desposits and lower muscle tissue devolpment (Hunt et al., 2001). Studies have shown that animals grown in traditional systems have the chance to get into contact with various natural vegetal flora which 
influnce the biochemical aspects of meat, have a higher amount of muscle tissue which leads to a beter consistency and also a superior technological quality (Lawrie et al., 2006; Morrissey et al., 2008).

The water holding capacity or drip loss, the ultimate $\mathrm{pH}$ and colour assessment are the three important parameters known to characterize the poultry and pork meat quality (Lee et al. 2000). By these predictors we can find quality deffects such as PSE (pale, soft, exudative) meat in pork or wooden breast (WB) in poultry (Tomovic et al., 2014b). Because poultry meat has become highly consumed and the demand is in continous growth, producers are enforced to stimulate the development rate of muscles in broilers. But this trend has led to the appearence of a breast muscle quality defect (Dalle Zotte et al. 2015), an emergent myopathy called Wooden Breast (WB) (Sihvo et al. 2013). Consumers choose their products based on the aspect but when the product is already cooked these aspects are altered by the preparation process and additives. That is why the quality of the raw material used in restaurants or fast food units is very important to be maintained. Romania has shown a rapid growth after the comunist era in the food industry sector. This growth was more noticeable in the fast food industry, processed foods like shaorma, hamburgers, kebab which are common food items in many of these units. Normally the raw meat is provided by large scale units and the quality is not always the same as the consumers would believe or want. That is why studies that can proove the beneficial aspects of cooking your own food, where you can buy the raw meat and assess its quality before cooking are important to draw the attention of the population. Currently in Romania there aren't a lot of data regarding this fact and research studies that compare meat quality according to the breeding system are very scarced.

This study aims to assess the quality and technological aspects of raw meat used for cooking in fast-food units and compare it with the one obtained in a traditional system in order to reveal the possible differences.

\section{Materials and methods}

\section{Sampling}

Samples were gathered from the refrigerating areas of ten fast-foods units. The samples used for assessing the water holding capacity were taken from two slaughtering units that provide with meat the fast-food units studied. The meat samples analysed were as follows: poultry breast $(n=30)$, weight $1000 \mathrm{~g} /$ package, deboned poultry legs $(n=30)$, weight $1000 \mathrm{~g} /$ package, pork leg $(n=30)$, weight $2000 \mathrm{~g} /$ package. In order to evaluate the possible difference between breeding systems we have gathered samples from two small-scale production units, one for poultry and one for pigs, which are authorized for selling traditional products on the market. The number of samples was as follows: poultry breast $(n=20)$, deboned poultry legs $(n=10)$, pork leg $(n=30)$. After the collecting of the samples in their original packages the biochemical analyses were performed in the same day in the Food Inspection Laboratory from the University of Agricultural Sciences and Veterinary Medicine Cluj-Napoca.

\section{Sensorial and compositional quality evaluation}

In the sensorial evaluation of pork and poultry meat we have established the exterior aspect, characteristics of fat tissue, colour, consistency and smell. For the compositional paramaters, such as water percent, fat, protein, collagen, we used the FoodScan Lab (Foss, Germany) spectrophotometer.

Evaluation of technological quality

The aspects evaluated for showing particular technological aspects were related to colour and consistency of muscle fibers, using the HunterLab spectrophotometer (Hunterlab, USA) and the water holding capacity (WHC).

Meat samples were collected as mentioned earlier from the slaughtering line of two processing plants at $2 \mathrm{~h}$ post mortem. Meat was also analysed and segregated into two groups according to the $\mathrm{pH}$ and colour values (L*a*b*) (HunterLab, USA). At 2 and 7 days post-mortem the samples were tested for the WHC. The WHC was measured by gravimetric drip loss method (Wilborn et al., 2004). 


\section{Statistical analysis}

The results regarding the prevalence and possible difference between the two slaughter house units investigated were statistically analysed with the Origin 8.5 program, using the single factor categorical analysis system ANOVA.

\section{Results and discussions}

At the sensorial exam of the poultry meat samples, the surface was covered by a dry layer, the muscle tissue was compact, dense and elastic, the colour depending on the area being more whitish in the breast and more pink in the legs. Concerning is the fact that in some of the breast meat samples gathered from the processing plants we found a pathological condition that may influence the technological quality and that is the „woody breast” lesion which is characterized by a hard consistency of the Pectoralis major muscle. Also we noticed a more swollen aspect at the exterior of this muscle, a more pale colour and the occurrence of white stripes (Figure 1).

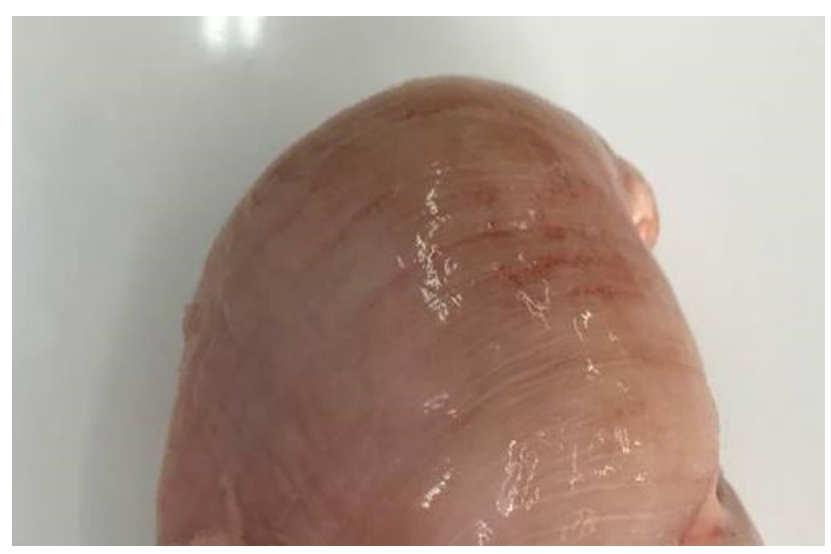

Figure 1. Aspects of beast muscle affected by woody breast condition

Normally there are histological modifications which include the degenerescence of protein muscles, their regeneration and the accumulation of conjunctive tissue (Sihvo et al., 2014). The degenerescence of muscle proteins led to a lowering of protein functions, having a negative impact on the quality of poultry meat products and also on their sensorial characteristics. Studies have shown that this modification leads to higher cooking losses and lower water holding capacity (Mudalal et al., 2015; Petracci et al., 2014).

In the case of porl meat the sensorial analysis did not show abnormalities. All the samples were in conformity to a fresh like looking meat, showing a dry layer on the surface, pink-reddish colour, elastic and soft consistency.

Following the colorimetric analyses with the HunterLab spectrophotometer, there were important aspects underlined which influenced the values. As shown in fig. 2 , the breeding systems has a very strong influence on $\mathrm{L}^{*}$ values. In the case of industrially obtained pork meat this value had an average of $62.1 \%$ while in the traditionally obtained pork meat this was $45.8 \%$. This fact proves that the traditionally obtained meat is darker in colour while the industrially obtained one is lighter.

The values obtained in the case of poultry meat examined are shown in Table 1.

As shown in table 1, the percentage of drip loss measured in two days post-mortem is high compared to the values obtained in the traditional system samples. The differences were also statistically relevant $(\mathrm{p}<0.05)$. There was also a direct relation between the percentage of drip loss and the luminosity values registered in the meat samples. The higher the $L^{*}$ and $b$ values the higher the drip loss values. We can state that if meat has a lighter colour it has also a lower water holding capacity.

The drip loss measuring indicates the potential of losing water during the refrigerating storage period of the analysed samples. This fact is very important for the technological quality given that after slaughtering process meat is always stored in refrigerating conditions.

In case of pork meat the obtained values are shown in Table 2.

In case of pork meat the variations were much lower than the case of poultry meat. The $L^{*}$ values were around $71 \%$ percent in both cases even though the colour in case of the industrially obtained meat was lighter. Evaluating the drip loss values in both breeding systems we revealed that the losses are not so high.

The compositional aspects were also different, taking into account the muscle area and also the breeding system. As shown in Figure 3, breast muscles have a lower water content, more fat, lower protein level and higher collagen values. 


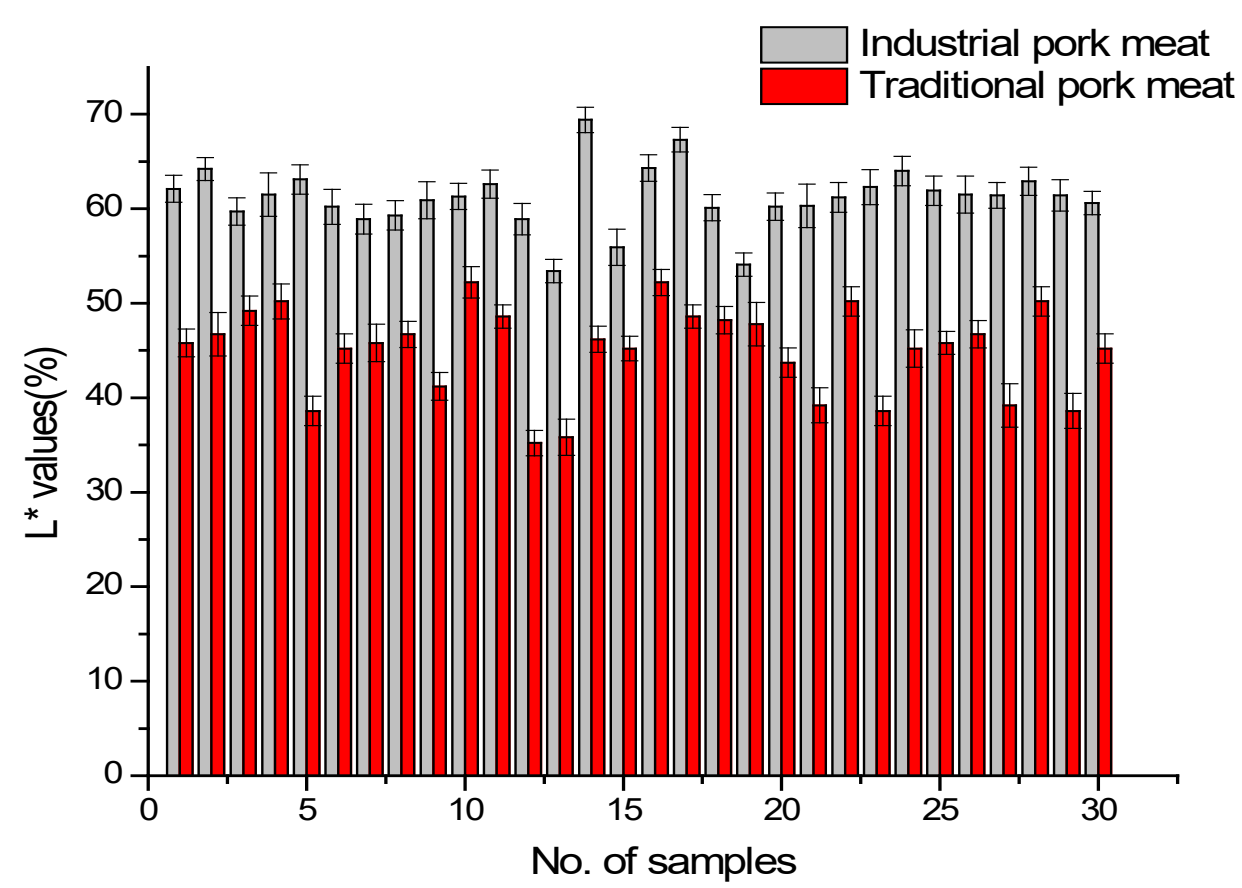

Figure 2. Luminosity values obtained with HunterLab apparatus in case of pork meat

Table 1. Values of the parameters established for technological quality assessment of poultry meat

\begin{tabular}{|c|c|c|c|c|c|c|}
\hline \multirow[t]{2}{*}{ Parameter } & \multicolumn{3}{|c|}{$\begin{array}{l}\text { Poultry meat industrial } \\
\text { system }(n=20)\end{array}$} & \multicolumn{3}{|c|}{$\begin{array}{l}\text { Poultry meat traditional } \\
\text { system }(n=20)\end{array}$} \\
\hline & Average & SD & Variation & Average & SD & Variation \\
\hline Initial weight (g) & 370.23 & 32.12 & $89-210.3$ & 260.12 & 35.2 & $99.3-276.4$ \\
\hline Humidity (\%) & $75.6 \%$ & 1.2 & $70.2-79.3$ & 70.2 & 0.89 & $68.9-76.1$ \\
\hline Luminosity & 62.1 & 3.2 & $53.2-72.4$ & 45.8 & 2.31 & $38.9-56.3$ \\
\hline Value wave a & 0.4 & 0.7 & $-2.3-1.2$ & 0.8 & 0.5 & $-0.4-1.8$ \\
\hline Value wave b & 14 & 3.1 & $8.9-17.9$ & 9.8 & 3.5 & $6.5-17.9$ \\
\hline pH (24h) & 5.86 & 0.16 & $5.82-5.9$ & 5.92 & 0.32 & $5.62-6.1$ \\
\hline pH (7 days) & 6.22 & 0.54 & $6.04-6.4$ & 6.32 & 0.63 & $6.12-6.57$ \\
\hline $\begin{array}{l}\text { Quantity drip } \\
\text { loss (\%) } 2 \text { d }\end{array}$ & 2.35 & 1.02 & $0.78-3.42$ & 0.52 & 0.18 & $0.34-1.12$ \\
\hline $\begin{array}{l}\text { Quantity drip } \\
\text { loss (\%) } 7 \text { d }\end{array}$ & 5.3 & 1.32 & $4.34-6.66$ & 1.69 & 0.68 & $0.95-2.47$ \\
\hline
\end{tabular}

The compositional parameters vary also according to the breeding system as seen in Figure 4. At the breast meat samples we found that industrially obtained meat used in fast food units show higher water, higher fat values and lower protein and collagen levels.

In case of pork meat the results were similar to the ones obtained in poultry meat, meaning that industrially obtained pork meat has lower compositional quality revealed by markedly lower amounts of protein and higher amounts of fat. When comparing the average values found in both breeding systems we found that each parameter investigated (water, protein, fat, collagen) is statistically different $(p<0.05)$. The average value of proteins found in the traditionally obtained 
Table 2. Values of the parameters established for technological quality assessment of pork meat

\begin{tabular}{l|c|c|c|c|c|c}
\hline \multirow{2}{*}{\begin{tabular}{l} 
Parameter \\
\cline { 2 - 8 }
\end{tabular}} & \multicolumn{2}{c}{$\begin{array}{c}\text { Pork meat industrial } \\
\text { system (n=20) }\end{array}$} \\
\cline { 2 - 8 } Initial weight (g) & 89.23 & 12.12 & $81-110$ & 92.43 & 3.2 & $90.3-111.4$ \\
\hline Humidity (\%) & 74.2 & 1.42 & $70.2-74.3$ & 71.22 & 3.49 & $64.29-73.1$ \\
\hline Luminosity & 51.2 & 1.2 & $55.32-60.3$ & 46.82 & 1.31 & $36.19-50.23$ \\
\hline Value wave $\boldsymbol{a}$ & 0.74 & 0.7 & $-1.3-1.1$ & 0.97 & 0.34 & $-0.7-1.82$ \\
\hline Value wave $\boldsymbol{b}$ & 8.5 & 1.21 & $8.39-11.9$ & 9.84 & 2.5 & $7.5-15.19$ \\
\hline pH (24h) & 5.56 & 0.16 & $5.52-5.93$ & 5.72 & 0.32 & $5.42-6.16$ \\
\hline pH (7 days) & 6.12 & 0.54 & $5.78-6.23$ & 5.97 & 0.8 & $5.86-6.3$ \\
\hline Quantity drip loss (\%) 2 d & 1.15 & 0.67 & $0.97-4.14$ & 1.12 & 0.18 & $0.34-1.12$ \\
\hline Quantity drip loss (\%) 7 d & 3.3 & 1.32 & $4.34-6.66$ & 2.69 & 0.68 & $0.95-2.47$ \\
\hline
\end{tabular}

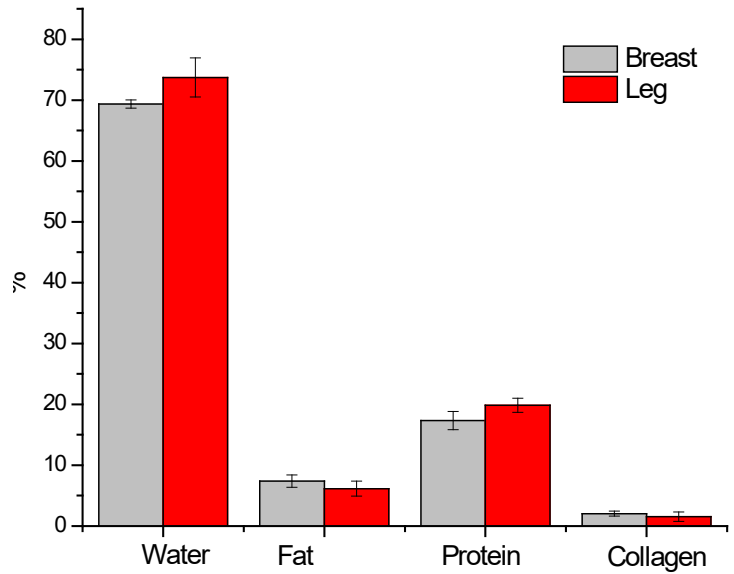

Figure 3. The average values found in poultry meat according to the region

pork meat was $27.46 \%$ and the one obtained in the industrially produced meat destined for fastfoods was $20.17 \%$.

\section{Conclusion}

Meat destined for fast-food products has a lower technological and compositional quality. The fact that meat shows more fat and less proteins reveals the negative aspect of choosing these types of products. Meat destined for fastfood industry has a higher drip loss and lower water holding capacity showing a poorer quality in cooking. Industrial chicken breeding systems favour the appearance of pathologies such as

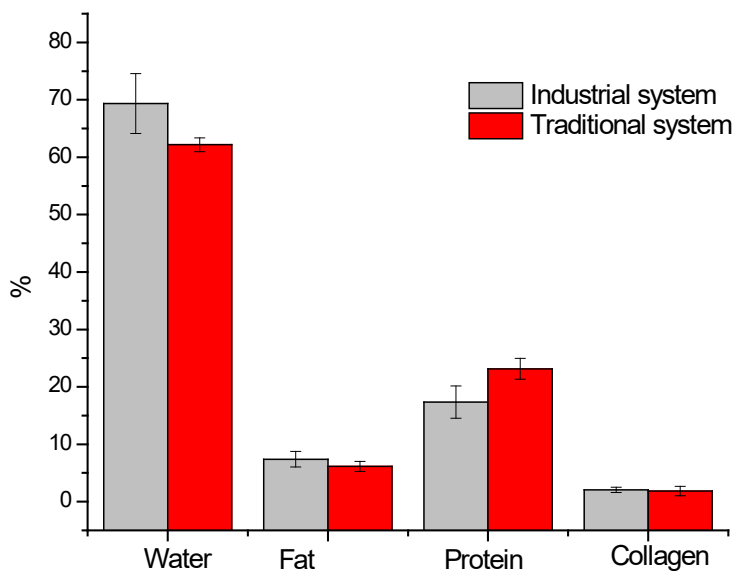

Figure 4. The average values of the poultry breast meat samples analysed

wooden breast, which affect the quality of meat. None of the traditionally obtained meat showed sensorial or technological modifications.

Acknowledgments: This research did not receive any specific grant from funding agencies in the public, commercial, or not-for-profit sectors.

\section{References}

1. Abdullah AY, Muwalla MM, Matarneh SK, Ishmais MAA (2010). Effects of strain on performance, and age at slaughter and duration of post-chilling aging on meat quality traits of broiler. Asian-Australasian Journal of Animal Science 23: 1645-1656.

2. Brewer MS, Sosnicki A, Field B, Hankes R, Ryan KJ, Zhu LG, McKeith FK (2004). Enhancement effects on quality 
characteristics of pork derived from pigs of various commercial genetic backgrounds. J. Food Sci., 69: 5-10.

3. Dalle Zotte A, Tasoniero G, Russo E, Longoni C, Cecchinato $M$ (2015). Impact of coccidiosis control program and feeding plan on white striping prevalence and severity degree on broiler breast fillets evaluated at three growing ages. Poultry Science, 94: 2114-2123.

4. Edwards DB, Bates RO, Osburn W (2003). Evaluation of Duroc- vs. Pietrain-sired pigs for carcass and meat quality measures. J. Anim. Sci., 81: 1895-1899.

5. Fletcher DL (2002). Poultry meat quality. Worlds Poult. Sci. J. 58:131-145.

6. Hunt MC, Acton JC, Benedict RC, Calkins CR, Cornforth D, Jeremiah LE, Olson D G, Salm CP, Savell JW, Shivas SD (2001). Guidelines for meat colour evaluation. Proceedings of 44th Annual Reciprocal Meat Conference. American Meat Science Association and National Live Stock and Meat Board, Manhattan, USA, 1-17.

7. Lawrie RA, Ledward DA (2006). Lawrie's meat science (7th ed.), Cambridge, UK : Woodhead Publishing Ltd. and CRC Press LLC.

8. Lee S, Norman JM, Gunasekaran S, van Laack RLJM, Kim BC, Kaufmann RG (2000) Use of Electrical Conductivity to Predict Water Holding Capacity in Post-Rigor Pork. Meat Science, 55: 385-389.

9. Monin H (1998). Recent methods for predicting quality of whole meat. Meat Science 49: S231- S243.

10. Morrissey ER, Jacob RH, Pluske JM (2008). Perception of red brown colour by consumers. Proceeding of the 54th International Congress of Meat science and Technology,
Session 9.7, 10-15 August 2008, Cape Town, South Africa, 1-3.

11. Mudalal S, Lorenzi M, Soglia F, Cavani C, Petracci M (2015). Implications of white striping and wooden breast abnormalities on quality traits of raw and marinated chicken meat. Animal, 9(4): 728- 734.

12. Petracci M, Fletcher DL, Northcutt JK (2001). The effect of holding temperature on live shrink, yields and breast meat quality of broiler chicken. Poult. Sci. 80:670-675.

13. Petracci M, Mudalal S, Babini E, Cavani C (2014). Effect of white striping on chemical composition and nutritional value of chicken breast meat. Italian Journal of Animal Science 13: 179-183.

14. Sihvo HK, Immonen K, Puolanne E (2013). Myodegeneration with fibrosis and regeneration in the pectoralis major muscle of broilers. Veterinary Pathology, 51: 619-623.

15. Sihvo HK, Immonen K, Puolanne E (2014). Myodegeneration with fibrosis and regeneration in the pectoralis major muscle of broilers. Vet. Pathol. 51: 619623.

16. Tomovic VM, Zlender BA, Jokanovic MR, Tomovic MM, Sojic V, Skaljac S, Kevresan ZS, Tasic TA, Ikonic PM, Soso MM (2014a). Sensory, physical and chemical characteristics of meat from freerange reared Swallow-belly Mangulica pigs, J. Anim. Plant Sci., 24: 704-713.

17. Tomovic VM, Zlender BA, Jokanovic MR, Tomovic MS, Sojic BV, Skaljac SB, Tasic TA, Ikonic PM, Soso MM, Hromis, NM (2014b) Technological Quality and Composition of the M. Semimembranosus and M. Longissimus Dorsi from Large White and Landrace Pigs. Agriculture and Food Science, 23: 9-18.

18. Wilborn BS, Kerth CR, Owsley WF, Jones WR, Frobish LT (2004). Improving pork quality by feeding supranutritional concentrations of vitamin D3. J. Anim. Sci., 82: 218-224. 